\title{
Antecedents of satisfaction with teamwork in higher education: An empirical study
}

\author{
Dr S. Pavan Kumar \\ Associate Professor \& Head, School of Management, \\ National Institute of Technology Karnataka (NITK), Surathkal \\ pavankumar@nitk.ac.in
}

\begin{abstract}
Developing a theoretical framework to understand undergraduate student teamwork dynamics has always been a topic of interest for educational researchers. Essentially, this is because teamwork is seen as a method for learning and professional development as many companies allocate their work in teams. Hence, there is a need for researchers to look into the underlying factors that can influence teamwork effectiveness among university students. Although there exist a few studies on identifying the antecedents of satisfaction with teamwork, this study intends to analyses the influence of task factors, such as workload, and individual factors, such as collaborative behaviour, on satisfaction with teamwork and expected quality respectively. In addition, the study was also employed to understand the role of team cohesiveness and individuals having knowledge, skills and abilities on satisfaction with teamwork and expected quality respectively. Data were collected from 151 students who are studying their undergraduate course in Indian universities. The proposed causal relationship was examined with SmartPLS 3, as it allows us to analyse multiple causal relationships in a single framework. The findings show that workload has significant negative relationship with both satisfaction with teamwork and team cohesiveness. Whereas, team cohesiveness in turn has a significant positive relationship with satisfaction with teamwork. Similarly, collaborative behaviour has emerged as significant predictor of individual's knowledge, skills and abilities, and expected quality from a teamwork. In turn, it was identified that individual's knowledge, skills and abilities could influence both team cohesiveness and expected quality. The findings of the study have implication to both the administrators and teachers involved in designing and deploying the coursework to university students.
\end{abstract}

Keywords: Satisfaction with teamwork, team cohesiveness, workload, collaborative behaviour, having knowledge, skills, and abilities and expected quality.

\section{Introduction}

Many higher educational institutions and universities have started recognising the importance of teamwork skill among its students. There are a few institutions where teamwork is even seen as a pedagogical tool. There are various reasons for this elevated interest on teamwork and its effectiveness. The first and primary reason comes from business entity, where effective teamwork is considered as the secret behind growth and success. Many companies allocate their responsibilities in teams composed of employees from different areas (Curşeu, Janssen, \& Raab 2012). Work involving teams are considered to be more efficient and effective than individual work (Hoegl \& Gemuenden, 2001). However, business entities assume that member of a team should have an ability to deliver both as an individual as well as in a team with the other employees of the organisation as its members. The second reason comes from certain agencies that offer recognition to educational institutions. ABET Engineering Accreditation Commission (2004) emphasises to maintain some accreditation standards. One such standard is where university programs should design their curriculum in such a way that the students get ample opportunity to work in teams and demonstrate their ability to work in teams. Napier and Johnson (2007) and Chiriac (2008) have stressed the point that educators should integrate teamwork across the curriculum as a tool for learning and professional development. Teamwork can prepare students' and young minds for their future career opportunities. Hence, looking at the increasing emphasis on teams and teamwork, there is a need for more academic research. It is needed not only to identify the underlying factors that can influence team effectiveness, but also to find out how various factors impacting team effectiveness are related to one another (Fransen, Kirschner, \& Erkens 2011). In line with the need of the hour, current research paper intents to investigate on the factors that can lead to effectiveness of teams and expected quality as an output of teams' work from university students' perspective.

\section{Literature Review and hypotheses development}

Our academic textbooks have rich content that explains how teams are different from groups. Many of the definitions given in the books and other academic literature separate teams from groups in more than one way, mainly with reference to the characteristics possessed by individuals in a team environment. On one side of the coin, individuals in a team environment share an identity that is 
common to the team, i.e. in terms of having a common goal. Another side of the coin, individual in a team has a unique role to play within the team based on the kind of skill set he/she possesses. In total, members of the team are interdependent on one another team members while discharging the assigned tasks to influence on the functioning of the establishment (Morgeson, Lindoerfer, \& Loring, 2010).

A team-based work environment can contribute meaningfully to the functioning of an establishment only when there exists effective team functioning. The focus of most of the previous studies on teamwork has been on team effectiveness (Janz, Colquitt, \& Noe 1997). The difficult part of the study is in operationalising team effectiveness. Scholars in this domain of research have operationalised team effectiveness in many different ways. According to Hackman (1987), team effectiveness must capture the quality of team outcomes. As suggested in the I-P-O (InputProcess-Output) framework of McGrath (1964), the outcomes of teamwork include performance quality and team members' satisfaction. Thus, in the current research work, teamwork effectiveness is assessed in terms of satisfaction with teamwork and expected quality.

The other way of representing team functioning is team cohesiveness (Thompson, Haidet, Borges, Carchedi, Roman, Townsend, \& Levine, 2015). Team cohesion is perceived as the degree to which members of the team are connected psychologically to one another in realising team goals. Team cohesion influences academic performance (Thompson et al. 2015). In academic environment, teams' cohesiveness is positively related to students' learning (Williams, Duray, \& Venkateshwar, 2006). According to Bravo, Catalán, and Pina (2019), team cohesiveness has a significant positive effect on students' satisfaction with teamwork.

It can be understood that team cohesion depends on task complexities and characteristics. This is because there is a possibility that individuals in the team may act differently based on the task complexity and the workload assigned. A task complexity increases when the number of events and the degree of interactivity among the events increases (Sweller, 1994). In the institutes of higher learnings, team projects usually have a substantial workload. Students have to manage their time and efforts with different coursework load along with team activities while working on projects. Such a situation can lead to a feeling of overburden. Students perceive it difficult to implement a given task when they are made to deal with a large workload along with the complexity of work and with a lack of sufficient know-how (Kyndt et al. 2011b). It is clear to understand such a situation can have detrimental effects on their satisfaction with teamwork and on the team cohesiveness.

Scholars in the domain of teamwork have proposed certain behaviours and attributes that are vital for the outcome of teamwork. According to Stevens and Campion (1994), there are knowledge, skill, and ability which are required for teamwork. A few notable skills and abilities can be intelligence skills, and leadership skills etc. Such skills have the ability to help in enhancing group cohesion (Bravo at al. 2019). The demand from team members to possess a breadth of knowledge, skill and ability is often greater (Sundstrom, De Meuse \& Futrell, 1990). Individuals in teamwork environment who have control over knowledge, skills and abilities are expected to contribute to the expected quality work as an outcome. Previously, research has revealed that teams are not always better problem solvers than individuals (Libby, Trotman \& Zimmer, 1987). 'Zone of Proximal Development', a socio-cultural theory postulated by Vygotsky says that an individual learner needs help or feedback from a faculty member or from a fellow group member to understand a new idea, concept, or proposition (Ku, Tseng, \& Akarasriworn, 2013). According to Vygotsky's view, interaction with fellow group members will facilitate individual knowledge acquisition and cognitive growth (Vygotsky, 1978), which in turn can help individual learners in solving problems and support the organisations in realising its goals.

Based on the above findings and theoretical arguments, the following hypotheses were developed:

H1: Workload has a negative influence on satisfaction with teamwork

$\mathbf{H}_{2}$ : Workload has a negative influence on team cohesiveness

H3: Team cohesiveness has a positive influence on satisfaction with teamwork

H4: Collaborative behaviour has a positive influence on having knowledge, skills and abilities

H5: Having knowledge, skills and abilities has a positive influence on expected quality

H6: Collaborative behaviour has a positive influence on expected quality

H7: Having knowledge, skills and abilities has a positive influence on team cohesiveness

\section{Method}

A conceptual model was framed based on the gaps identified in the literature. The data were collected from graduate students studying in Indian higher education institutions. A total of 151 students have filled the survey instrument. Samples were drawn using convenience sampling method via both physical and google forms. Among the respondents, 79 percentage were male students and 21 respondents were female students. The median age of the respondents was 21 years. All the proposed causal relationships were verified using SmartPLS version 3, which is a PLS-SEM software. Students perception of Workload was measured using four indicators developed by Kyndt et al. (2011b). Measures of collaborative behaviour were adapted from the work of Gargallo, Suárez-Rodríguez, and Pérez-Pérez (2009), which have five items. Team cohesiveness was based on the work of Sargent and SueChan (2001), Pfaff and Huddleston (2003), and Fransen, Kirschner and Erkens (2011) as used in Bravo, Catalán, and Pina (2019), it had six indicators. Satisfaction with 
teamwork was assessed following Wageman, Hackman, and Lehman (2005) and Fransen, Kirschner, and Erkens (2011) as used in Bravo, Catalán, and Pina (2019), it had four items. One item was reverse coded and it was properly handled during data analysis. Having relevant knowledge, skills and abilities scale and Expecting quality scale were measures using four items each and were developed by Loughry, Ohland \& DeWayne Moore, (2007). The anchors for all the scales were on a 5-point Likert scale with a score of 1 = strongly disagree, 2 =disagree, $3=$ uncertain, 4-agree, and $5=$ strongly agree.

\section{Results}

\section{A. Descriptive Statistics}

Table 1: Showing descriptive statistics, Cronbach's Alpha Reliability coefficients, Composite Reliability, Correlations among latent variables, Average Variance Extracted (AVE) are shown in italics, and Square root of AVE values are shown in parenthesis.

\begin{tabular}{|c|c|c|c|c|c|c|c|c|c|c|}
\hline Variable & Mean & $\begin{array}{c}\text { Standard } \\
\text { Deviation } \\
\text { (SD) }\end{array}$ & $\begin{array}{l}\text { Reliability } \\
\text { (Croubach's } \\
\text { Alpha) }\end{array}$ & $\begin{array}{l}\text { Composite } \\
\text { Reliability }\end{array}$ & WL & TC & ST & СВ & HRK & EXQ \\
\hline WL & 2.87 & .816 & 0.768 & 0.849 & $.593(.770)$ & & & & & \\
\hline TC & 3.71 & .742 & 0.844 & 0.890 & $-593^{* *}$ & $.620(.787)$ & & & & \\
\hline ST & 3.49 & .757 & 0.778 & 0.864 & $-.706^{\ddagger \ddagger}$ & $.756^{\ddagger} \neq$ & $.635(.796)$ & & & \\
\hline CB & 3.92 & .767 & 0.846 & 0.891 & $-606^{f \neq}$ & $.720^{* \neq}$ & .687" & $.026(.791)$ & & \\
\hline HRK & 3.70 & .817 & 0.915 & 0.940 & $.309 * *$ & $516^{* *}$ & $.349^{\prime \prime}$ & $.448^{\prime \prime}$ & $.798(.893)$ & \\
\hline EXQ & 3.91 & .664 & 0.859 & 0.904 & $-306^{* *}$ & $.578^{* *}$ & $.535^{\prime \prime}$ & $.500^{\circ}$ & $.589^{*}$ & $.704(839)$ \\
\hline
\end{tabular}

Note: All correlations are significant at $* * p<.001$ level (2-tailed); WLWorkload, TC-Team Cohesiveness, ST-Satisfaction with Team, CB-Collaborative Behaviour, HRK-Having Knowledge, Skills, and Abilities, EXQ-Expected Quality

The values for Cronbach's alpha for all the scales used in the study were well above the recommended threshold value of .70 (Fornell \& Larcker, 1981). In addition to Cronbach's alpha, composite reliability of the scales used were also examined, all the scales possessed sufficient composite reliability. Validity of the scale items used in the current study was verified by both convergent and discriminant validity. Convergent validity ensures items of a referred construct converge towards a substantial portion of the variance that is in common. A very common way to check the presence of convergent is to verify AVE values greater than .5 (Hair et al., 1998). Discriminant validity refers to distinction from one another among the indicators of different constructs and a strong association of indicators with each other within the same construct. To verify the existence of discriminant validity, square roots of AVEs should be larger than the correlations between constructs. For the current study, the AVE and square root of AVE values was ranging from .593 to .798 and .770 to .893 respectively. Moreover, the square root of AVE values was much higher than the correlations between constructs. Hence, psychometric properties such as reliability, convergent validity, and discriminant validity were achieved (see table 1) for the scales used in the study. In addition, it is mandatory to see if there is any multicollinearity problem. High collinearity between two or more indicators can lead to bias in the results. Kock and Lynn (2012) suggests Variance Inflation Factor (VIF) of 3.3 or less to avoid the issues of multi-collinearity and high inter-associations among variables. The present study meets the criterion.

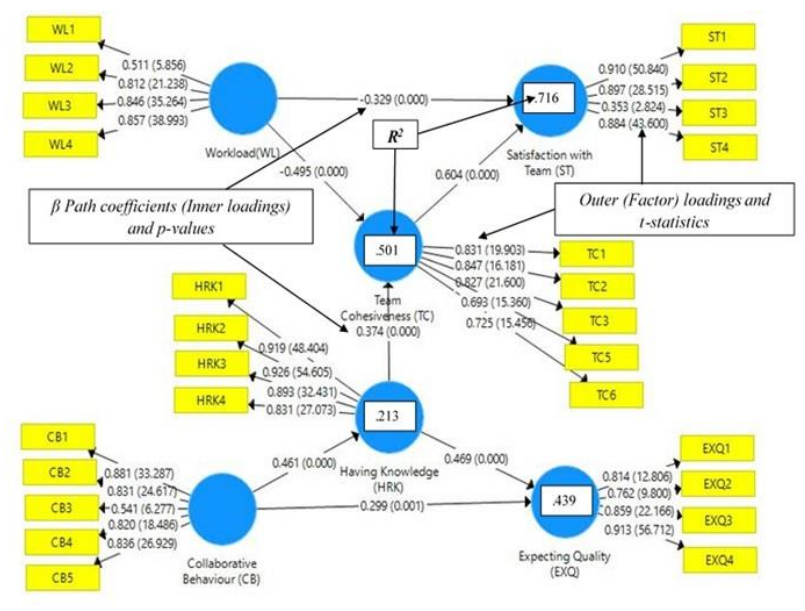

Figure 1: The $\beta$ path coefficient values (Inner loadings) along with $p$ values, Factor (Outer) loadings of Indicators along with t-statistics, and $R^{2}$ values are shown. All the loadings are significant at $p<.001$ or at $p=0.001$, except one indicator 'TC4' of team cohesiveness which was deleted as it was not properly loading to the factor and also was non-significant at $p<.001$. $\beta$ path coefficient between all the proposed hypotheses were significant. All the item loadings on their respective constructs were measured above .50. and all were significant at $p<.001$.

\section{Model Quality}

Once the psychometric properties of the model are established, hypothesised causal relationships and the quality of the model were accessed. PLS-SEM (Partial least squares - Structural equation modeling) does not have a standard goodness-of-fit statistic (Henseler \& Sarstedt, 2013). Instead, the model quality is evaluated based on the ability of its exogenous constructs in predicting the endogenous constructs.

Coefficient of determination $R^{2}$ is a measure of the model's predictive accuracy and it ranges from 0 to 1 , where 1 represents complete predictive accuracy. For the present proposed model, the $R^{2}$ value is .716 for satisfaction with the team (ST), .501 for team cohesiveness (TC), .439 for expected quality (EXQ), and .213 for having knowledge, skills and abilities (HRK) constructs. Rule of thumb in methodological research says that an acceptable $R^{2}$ with $0.75,0.50,0.25$, respectively, describing substantial, moderate, or weak levels of predictive accuracy (Hair et al., 2011). Which essentially means that the exogenous constructs of the model have achieved nearly substantial to weak prediction accuracy. Hair Jr, Sarstedt, Hopkins, and Kuppelwieser, (2014) suggests considering adjusted $R^{2}$, as it is better statistics even when additional constructs are added to the model. For the present model, even the adjusted $R^{2}$ values are at .713 for ST, .494 for TC, .431 for EXQ, and .208 for HRK constructs. According to Falk and Miller (1992), the strength of each path of a structural model and the $R^{2}$ coefficients of endogenous variables should be greater than .1. The adjusted $R^{2}$ value of students' satisfaction with team is .713. It means that the exogenous constructs of the model, i.e., workload and team 
cohesiveness put together explains 71.3 percentage of variance in students' satisfaction with team, which nearly substantial level of predictive accuracy. Similarly, the adjusted $R^{2}$ value of expected quality is .431. This essentially means that collaborative behaviour of the students and having knowledge, skills and abilities put together explains 43.1 percentage of variance in expected quality, which secured nearly moderate level of predictive accuracy.

Table 2. Summary of hypothesised causal relationship results

\begin{tabular}{ccccc}
\hline $\begin{array}{c}\text { Sl. No. of } \\
\text { Hypothesis }\end{array}$ & $\begin{array}{c}\text { Hypothesised } \\
\text { Relations }\end{array}$ & Path Coefficients $(\beta)$ & t-statistic & Result \\
\hline $\mathrm{H}_{1}$ & WL $\rightarrow$ ST & $-0.329^{* *}$ & 4.856 & Accepted \\
$\mathrm{H}_{2}$ & WL $\rightarrow$ TC & $-0.495^{* *}$ & 7.375 & Accepted \\
$\mathrm{H}_{3}$ & TC $\rightarrow$ ST & $0.604^{* *}$ & 9.972 & Accepted \\
$\mathrm{H}_{4}$ & $\mathrm{CB} \rightarrow$ HRK & $0.461^{* *}$ & 4.483 & Accepted \\
$\mathrm{H}_{5}$ & HRK $\rightarrow$ EXQ & $0.469^{* *}$ & 5.141 & Accepted \\
$\mathrm{H}_{6}$ & $\mathrm{CB} \rightarrow$ EXQ & $0.299^{*}$ & 3.318 & Accepted \\
$\mathrm{H}_{7}$ & HRK $\rightarrow \mathrm{TC}$ & $0.374^{* *}$ & 5.201 & Accepted \\
\hline
\end{tabular}

Note: $\quad * *$ significant at $p<.001, *$ significant at $p=.001$, WL-Workload, TC-Team Cohesiveness, ST-Satisfaction with Team, CBCollaborative Behaviour, HRK-Having Knowledge, Skills, and Abilities, EXQ-Expected Quality

PLS-SEM is used to create a path model based on a strong theoretical foundation (Hair et al., 2014). Figure 1 shows standardised regression $\beta$ coefficients for all the paths. It can be seen from table 2 , that workload has a significant negative influence on both satisfaction with team and team cohesiveness with $\beta=-.329, p<.001, \mathrm{t}=4.856$ and $\beta=-.495$, $p<.001, \mathrm{t}=7.375$ respectively. Hence, Hypotheses $\mathrm{H}_{1}$ and $\mathrm{H}_{2}$ were accepted. Team cohesiveness has a strong positive influence on satisfaction with team with $\beta=.604, p<.001$, $\mathrm{t}=9.972$ and therefore $\mathrm{H}_{3}$ is accepted. Collaborative behaviour has a significant positive influence on having knowledge, skills and abilities with $\beta=.461, p<.001$, $\mathrm{t}=4.483$ and hence $\mathrm{H}_{4}$ is accepted. Similarly, having knowledge, skills and abilities and Collaborative behaviour has positive influence on expected quality with $\beta=.469$, $p<.001, \mathrm{t}=5.141$ and $\beta=.299, p<.001, \mathrm{t}=3.318$ respectively and therefore $\mathrm{H}_{5}$ and $\mathrm{H}_{6}$ were accepted. Finally, having knowledge, skills and abilities has a significant positive influence on team cohesiveness with $\beta=.374, p<.001$, $\mathrm{t}=5.201$ and hence $\mathrm{H}_{7}$ is accepted.

\section{Discussion}

Students need to enjoy what they are doing. It could be an individual task or a team task. When it comes to a team task, students should derive satisfaction with the way they have jointly executed the task. They should feel that there is an advantage with the collaboration they had with the team members. Satisfaction with the teamwork can do wonders, because a student satisfied with his/her teammates would be willing to keep membership with the team to take up more challenging tasks in future. It might be possible that a student who enjoys his membership with cohesive team may not derive satisfaction with teamwork. However, in the current study, students who maintain a cordial relationship with other team members, and who gets going with the other team members to fulfil their part according to the terms and conditions agreed upon, are the ones who is satisfied with the teamwork. Hence, we can say that team cohesiveness is required for effective functioning of teams in educational institutions (Al-Rawi, 2008). Every student has a limitation on the amount of workload he/she can handle before things become out of control. It is expected that higher education in Indian universities has good amount of project work to be executed. If a student feels hard to work with a team, because of reasons such as, demands a lot of personal time, finds no support from the teachers' and peer group, and feels insecure in team environment, it can lead to adverse consequences. It impacts negatively on team cohesiveness and overall satisfaction on teamwork. Results are similar to what was presented by Bravo, Catalán, and Pina (2019). They found a negative influence of task factors on team cohesiveness. The student who enjoys the companionship of their respective classmates and reaches out to them for solving doubts is the one who improves their knowledge, skills and abilities. In turn, they to contribute to quality work. The findings of this study also indicate that individual factors such as knowledge, skills and abilities have a positive influence on team cohesiveness. The results of this study have implications for administrators of educational institutions and teachers alike. Teachers need to pay attention while allocating the workload. A collective action from all the faculty while allocating the work to the students would help in judiciously distributing the workload. It is very important as it influences their satisfaction with the teamwork. Similarly, teachers should walk an extra mile to support and help students' in solving some complex problems or where students need some support from teachers. Such a practice has significant impact on the quality of the final product.

\section{Limitations}

The study is based on cross-sectional survey data and one can think of replicating the study with longitudinal data to reinforce the findings of this research. Since the study employs convenient sample method, the results should be generalised with caution.

\section{Acknowledgement}

I appreciation my research scholar Mr Ansab K V for his support.

\section{References}

ABET Engineering Accreditation Commission. (2004). Criteria for accrediting engineering programs.

Al-Rawi, K. 2008. "Cohesiveness Within Teamwork: The Relationship to Performance Effectiveness - Case Study." Education, Business and Society: Contemporary Middle Eastern Issues 1 (2): 92-106.

Bravo, R., Catalán, S., \& Pina, J. M. (2019). Analysing teamwork in higher education: An empirical study on the antecedents and consequences of team cohesiveness. Studies in Higher Education, 44(7), 11531165. 
Chiriac, E. 2008. "A Scheme for Understanding Group Processes in Problem-Based Learning." Higher Education 55: 505-18.

Curşeu, P., S. Janssen, and J. Raab. 2012. "Connecting the Dots: Social Network Structure, Conflict, and Group Cognitive Complexity." Higher Education 63: 621-9.

F. Hair Jr, J., Sarstedt, M., Hopkins, L., \& G. Kuppelwieser, V. (2014). Partial least squares structural equation modeling (PLS-SEM) An emerging tool in business research. European Business Review, 26(2), 106-121.

Falk, R. F., \& Miller, N. B. (1992). A primer for soft modeling. University of Akron Press.

Fornell, C.G. and Larcker, D.F. (1981), "Evaluating structural equation models with unobservable variables and measurement error", Journal of Marketing Research, Vol. 18 No. 1, pp. 39-50.

Fransen, J., P. Kirschner, and G. Erkens. 2011. "Mediating Team Effectiveness in the Context of Collaborative Learning: The Importance of Team and Task Awareness." Computers in Human Behavior 27: 1103-13.

Gargallo, B., J. M. Suárez-Rodríguez, and C. Pérez-Pérez. 2009. "The CEVEAPEU Questionnaire. An Instrument to Assess the Learning Strategies of University Students." Relieve 15 (2): 1-31.

Hackman, J. R. 1987. “The Design of Work Teams.” In Handbook of Organizational Behavior, edited by J. W. Lorsch, 315-42.Englewood Cliffs, NJ: Prentice Hall.

Hair, J. F., Black, W. C., Babin, B. J., Anderson, R. E., \& Tatham, R. L. (1998). Multivariate data analysis (Vol. 5, No. 3, pp. 207-219). Upper Saddle River, NJ: Prentice Hall.

Hair, J.F., Ringle, C.M. and Sarstedt, M. (2011), "PLSSEM: indeed a silver bullet", Journal of Marketing Theory and Practice, Vol. 19 No. 2, pp. 139-151.

Henseler, J. and Sarstedt, M. (2013), "Goodness-of-fit indices for partial least squares path modeling", Computational Statistics, Vol. 28 No. 2, pp. 565-580.

Hoegl, M., \& Gemuenden, H. G. (2001). Teamwork quality and the success of innovative projects: A theoretical concept and empirical evidence. Organization Science, 12, 435-449.

Janz, B., J. Colquitt, and R. Noe. 1997. "Knowledge Worker Team Effectiveness: The Role of Autonomy, Interdependence, Team Development, and Contextual Support Variables.” Personnel Psychology 50 (4): $877-$ 904.

Kock, N., \& Lynn, G. (2012). Lateral Collinearity and Misleading Results in Variance-Based SEM: An Illustration and Recommendations. Journal of the Association for Information Systems, 13(7), 546-580.

$\mathrm{Ku}, \mathrm{H}$. Y., Tseng, H. W., \& Akarasriworn, C. (2013). Collaboration factors, teamwork satisfaction, and student attitudes toward online collaborative learning. Computers in human Behavior, 29(3), 922-929.

Kyndt, E., F. Dochy, K. Struyven, and E. Cascallar. 2011 b. "The Perception of Workload and Task Complexity and
Its Influence on Students' Approaches to Learning: A Study in Higher Education." European Journal of Psychology of Education 26 (3): 393-415.

Libby, R., Trotman, K. T., \& Zimmer, I. (1987). Member variation, recognition of expertise, and group performance. Journal of Applied Psychology, 72(1), 81.

Loughry, M. L., Ohland, M. W., \& DeWayne Moore, D. (2007). Development of a theory- ased assessment of team member effectiveness. Educational and psychological measurement, 67(3), 505-524.

McGrath, J. 1964. Social Psychology: A Brief Introduction. New York: Holt, Rinehart and Winston. Morgeson, F. P., Lindoerfer, D., \& Loring, D. J. (2010). Developing team leadership capability. The Center for Creative Leadership handbook of leadership development, 122, 285.

Napier, N., and R. Johnson. 2007. "Technical Projects: Understanding Teamwork Satisfaction in an Introductory IS Course." Journal of Information Systems Education 18 (1): 39-48.

Pfaff, E., and P. Huddleston. 2003. "Does It Matter If I Hate Teamwork? What Impacts Student Attitudes Toward Teamwork." Journal of Marketing Education 25 (1): 37-45.

Sargent, L. D., and C. Sue-Chan. 2001. "Does Diversity Affect Group Efficacy? The Intervening Role of Cohesion and Task Interdependence." Small Group Research 32 (4): 426-50.

Stevens, M. J., \& Campion, M. A. (1994). The knowledge, skill, and ability requirements for teamwork: Implications for human resource management. Journal of management, 20(2), 503-530.

Sundstrom, E., De Meuse, K. P., \& Futrell, D. (1990). Work teams: Applications and effectiveness. American psychologist, 45(2), 120.

Sweller, J. 1994. "Cognitive Load Theory, Learning Difficulty, and Instructional Design." Learning and Instruction 4: 295-312.

Thompson, B. M., Haidet, P., Borges, N. J., Carchedi, L. R., Roman, B. J., Townsend, M. H., ... \& Levine, R. E. (2015). Team cohesiveness, team size and team performance in team-based learning teams. Medical education, 49(4), 379-385.

Vygotsky, L. (1978). Mind in society: The development of higher psychological process. Cambridge, MA: Harvard University Press.

Wageman, R., J. R. Hackman, and E. Lehman. 2005. "Team Diagnostic Survey Development of an Instrument." The Journal of Applied Behavioral Science 41 (4): 373-98.

Williams, E. A., R. Duray, and R. Venkateshwar. 2006. "Teamwork Orientation, Group Cohesiveness, and Student Learning: A Study of the Use of Teams in Online Distance Education." Journal of Management Education 30 (4): 592-616. 